\title{
Droplet Impact, Spreading and Freezing on Metallic Surfaces of varying Wettability
}

\author{
Y. Pan, K. Shi, X. Duan, G. F. Naterer \\ Faculty of Engineering and Applied Science, Memorial University of Newfoundland, St. John's, NL, Canada \\ yp8367@mun.ca, kshi@mun.ca, xduan@mun.ca, gnaterer@mun.ca
}

\begin{abstract}
Ice formation and accumulation can lead to operational failure and risks for structures, including power transmission lines, aircraft, offshore platforms, marine vessels, and wind turbines. Liquid repellent and icephobic surfaces can reduce ice accretion and improve asset integrity and safety in harsh environments. There are significant needs to probe how wettability affects the droplet impact, ice nucleation and ice accretion processes on different kinds of micro-structured surfaces. This paper presents experimental results of droplet impact, icing delay time and ice accumulation on metallic surfaces with varying wettability. Several different designs of the hydrophobic surfaces are considered. A commercial hydrophobic coating is also used to enhance liquid repellent features and reduce ice accumulation. The results demonstrated that when the static contact angle increases, the total icing time increases, suggesting desirable icing delays. The total icing time decreases with lower surface temperature, higher impact velocity or smaller droplet diameter.
\end{abstract}

Keywords - superhydrophobic, anti-icing, wetting, freezing, icing-delay time

\section{INTRODUCTION}

In cold and harsh environments, the formation and accumulation of ice may cause significant hazards and hinder the field operations, for example, with power transmission lines, airplanes, offshore platforms, marine vessels, and wind turbine [1-4]. There are many ways to remove ice from structures, for example, with a high-frequency high-voltage short-circuit to melt the ice but it requires the operator to shut off power during de-icing operation [5-7]. Workers use hammers to remove the ice on wellhead platforms and chain bridges. These methods are inefficient, difficult, expensive, and often have safety and environmental issues [8]. In order to achieve a more effective way to reduce ice formation and adhesion, extensive research has been directed to develop hydrophobic metallic surfaces with water repellent and antiicing properties for applications in harsh environments [8, 910].

Superhydrophobic phenomena were first related to surface roughness by Dettre and Johnson [11]. Subsequently, the unique hydrophobic properties of lotus leaves have become an active research area because of the fundamental interests in wetting and directional flow of water [11]. The lotus effect has various advantages such as water repellent action, small flow resistance, and self-cleaning property from dirt. The static contact angle of a liquid droplet on a smooth surface is related to the following interfacial energies at the three phase contact line,

$$
\cos \theta=\frac{\gamma_{s v}-\gamma_{s l}}{\gamma_{l v}}
$$

where $\theta$ is the static contact angle. $\gamma_{s v}, \gamma_{l v}$, and $\gamma_{s l}$ represent the solid-vapor, liquid-vapor, and solid-liquid interfacial tensions, respectively. The contact angle hysteresis is also a key property to define the surface wettability. It is the difference between the advancing angle and receding angle when the solid surface is tilted, and the droplet starts to roll off [12-14]. The key properties of superhydrophobicity include the static contact angle larger than $150^{\circ}$ and small contact angle hysteresis (less than $10^{\circ}$ ).

For droplet impact dynamics, Ted Mao et al. [15] developed a semi empirical model to predict the maximum spread as a function of the Reynolds number (Re), the Weber number (We), and the static contact angle. Ice nucleation submodel is also considered as heterogeneous ice nucleation at liquid-solid interface and the free-energy barrier $(\Delta \mathrm{G})$ is also estimated by N. H. Fletcher [16].

$$
T_{\text {interface }}=T_{\text {droplet }}+\left(T_{\text {substrate }}-T_{\text {droplet }}\right) \frac{\operatorname{erfc}\left(\frac{h}{2 \sqrt{a_{n s} t_{c}}}\right)}{\operatorname{erfc}\left(\frac{h}{2 \sqrt{a_{w} t_{c}}}\right)}
$$

where $a_{n s}$ and $a_{w}$ are thermal diffusivities of solid-air and water domain, respectively and $t_{c}$ is the total time that the droplet in contact with substrate.

In this paper, experimental studies are conducted to determine the effects of sample surface temperature, droplet impact speed, surface wettability, and droplet diameter on the total icing time of a single water droplet. 


\section{EXPERIMENTAL APPARATUS AND PROCEDURE}

An experimental apparatus was designed to investigate liquid droplet impact and icing on surfaces with varying wettabilities. Fig. 1 shows the experimental setup. It consists of a support stand (Fisher Scientific) with a tilt base (World Precision Instruments) of adjustable inclination angles, a cold plate (AAVID Thermally) that is mounted on the tilt base and controls the temperature of sample surfaces, and a thermal electric cooler (TE Technology). A small copper tube (SigmaAldrich, Stainless steel capillary tubing 1/16 in) is buried for generating the liquid droplets with controllable temperatures. To generate a small water droplet, several needles of different inner diameters were used at the bottom end of the droplet generator tubing. The liquid comes from a syringe pump (Harvard). The cold plate is connected to a thermal bath (Fisher Scientific) which provides control of the surface temperature of the material sample being tested.

With this setup, water droplets are emitted with controlled temperatures impacting on different surfaces under different temperatures. High speed imaging was conducted with a highspeed camera (Vision Research). The high-speed camera was connected to a laptop for video and photo. An LED light and a light diffuser (Edmund Optics) were used to provide light while capturing droplet impact and nucleation processes. The response of the oscillation time, droplet dynamics and total icing time were determined from the video taken by the highspeed camera. The uncertainty analysis of the equipment used is shown in table 1.

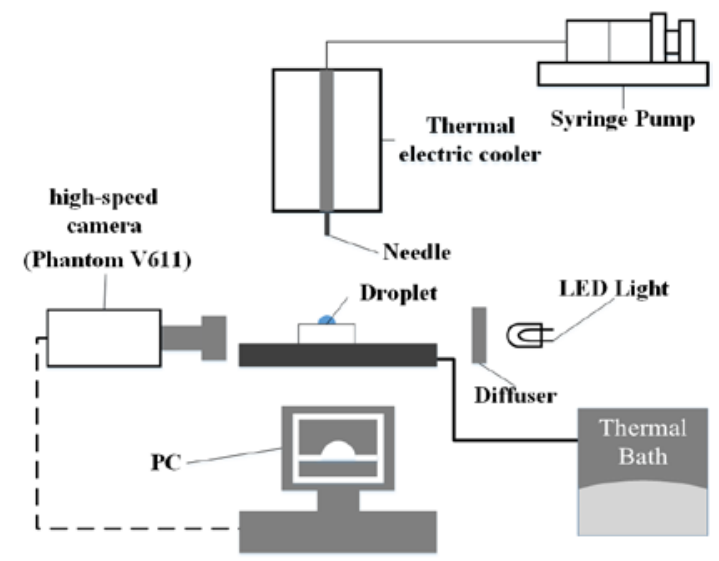

Fig. 1 Liquid droplet impact and icing experimental systems

Table 1. Experimental uncertainties of the experiments

\begin{tabular}{|c|c|c|}
\hline & Operating Range & $\begin{array}{c}\text { Uncertaint } \\
\mathrm{y}\end{array}$ \\
\hline Thermal Electric Cooler & -20 to $80^{\circ} \mathrm{C}$ & $\pm 0.1^{\circ} \mathrm{C}$ \\
\hline FLIR E60 Infrared Camera & -20 to $650^{\circ} \mathrm{C}$ & $\pm 2^{\circ} \mathrm{C}$ \\
\hline $\begin{array}{c}\text { Isotemp Heated Bath } \\
\text { Circulators }\end{array}$ & -25 to $200^{\circ} \mathrm{C}$ & $\pm 0.01^{\circ} \mathrm{C}$ \\
\hline Measure tape & MAX $25^{\prime}$ & $\pm 0.5 \mathrm{~mm}$ \\
\hline Measure ruler & MAX $15 \mathrm{~cm}$ & $\pm 0.5 \mathrm{~mm}$ \\
\hline High Speed Camera & $\begin{array}{c}\text { MAX } 6242 \text { fps with full } \\
\text { resolution }\end{array}$ & $\pm 20 \mathrm{~ns}$ \\
\hline
\end{tabular}

Several machined and coated sample surfaces with various wettabilities were used in the experiment. The contact angles of various samples are between $77.2^{\circ}$ and $145.5^{\circ}$ including hydrophilic and hydrophobic surfaces. The surface material is stainless steel (17-4 PH) for all samples. The smooth sample is a normal stainless-steel surface with no mechanical machining and coating. Some samples have microscale surface structures fabricated by wired electrical discharge machining, laser maching [17], or sandblasting. Other samples are coated with low surface energy material to further increase the surface hydrophobicity. The coating used for the samples was a Metal Repellency Treatment coating from Aculon.

\section{RESULTS AND DISCUSSION}

The droplet dynamics and ice nucleation experiments on a flat surface were conducted under different conditions and captured by high-speed camera. The temperature of the sample surface was varied between $-10^{\circ} \mathrm{C}$ and $-13^{\circ} \mathrm{C}$. The droplet diameters were varied from $1.80 \mathrm{~mm}, 2.82 \mathrm{~mm}$, to $4.11 \mathrm{~mm}$. The droplet impact speeds were varied from $0.77 \mathrm{~m} / \mathrm{s}, 0.99$ $\mathrm{m} / \mathrm{s}$, to $1.17 \mathrm{~m} / \mathrm{s}$. The droplet temperature was kept at $5^{\circ} \mathrm{C}$. The surface wettability was changed from a hydrophilic smooth stainless-steel surface to a hydrophobic textured stainless-steel surface.

To better describe the dynamics of the droplet after impinging on the flat surface, a coordinate system is defined as shown in Fig. 2. The moment at which a water droplet first impacts the sample surface is named as the impact point. The $\mathrm{x}$-axis is parallel to the sample surface and the $\mathrm{y}$-axis is perpendicular to the sample surface, and it is positioned in the middle of the droplet. Fig. 3 clearly indicates a typical droplet impact and nucleation process on a flat smooth surface. Kinetic energy, surface tension, air drag, liquid viscosity, and surface structure play important roles during the droplet impact process. The surface temperature, droplet size, and surface wettability play important roles during the droplet nucleation process. In general, the water droplet goes to a dynamic phase after impacting the sample surface, and the ice nucleation phase (phase change) occurs after the dynamic phase. The dynamic phase contains: a spreading phase (Fig. 3 b-e); a retraction phase (Fig. $3 \mathrm{f}-\mathrm{i}$ ); and a relaxation phase which contains many cycles of spreading and retraction processes. The dynamic phase lasted $334 \mathrm{~ms}$ before moving into an ice nucleation phase.

The impact process of a water droplet $(\mathrm{D}=2.82 \mathrm{~mm}$ ) on the smooth sample surface at the temperature of $-10^{\circ} \mathrm{C}$ and impact speed at $0.77 \mathrm{~m} / \mathrm{s}$ is shown in Fig. 3. After hitting the sample surface, a lamella was formed from the base of the water droplet, and then a ring was formed. Most of the volume of the droplet stayed in the outside ring instead of inside the lamella (Fig. 3 b-e). At the end of the spreading phase, the water droplet reached its maximum contact diameter which is 5.31 $\mathrm{mm}$ (Fig. $3 \mathrm{e}$ ). The total spreading process lasted for $8 \mathrm{~ms}$. The retraction phase started right after the spreading phase (Fig. $3 \mathrm{f}$ i). During the retraction phase, the water droplet started to recoil from the outside ring to the inside lamella. After the relaxation phase which contained a number of cycles of spreading and retraction phases, the droplet became steady and 
reached its equilibrium state for about $334 \mathrm{~ms}$. The ice nucleation phase started after the dynamic phase, and the water droplet took about $12.9 \mathrm{~s}$ to freeze. The droplet freezing process initiated at the liquid-solid interface (Fig. $3 \mathrm{i}$ ), and it propagated to the top of the droplet (Fig. $3 \mathrm{k}$ ). A small tip was formed on the top of the droplet at the end of the ice nucleation phase (Fig. 3 l).

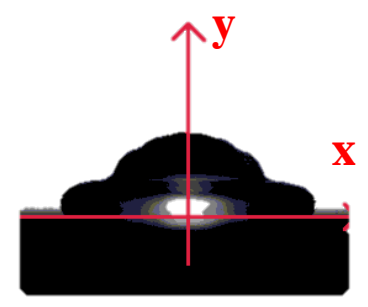

Fig. 2 Coordinate system of droplet impact and movement

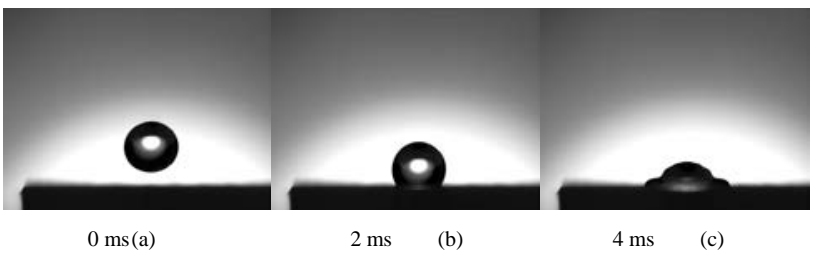

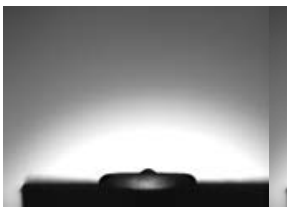

$6 \mathrm{~ms}$

(d)

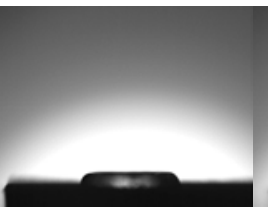

$8 \mathrm{~ms} \quad(\mathrm{e})$

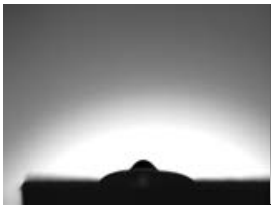

$12 \mathrm{~ms} \quad(\mathrm{~g})$

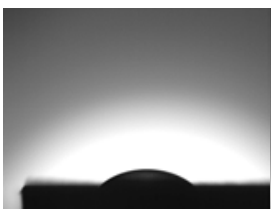

$334 \mathrm{~ms}$

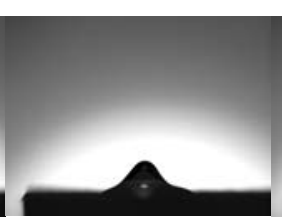

$14 \mathrm{~ms} \quad$ (h)

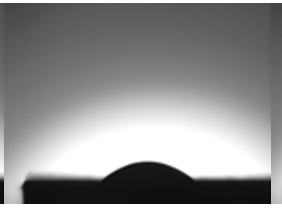

$8.774 \mathrm{~s}$
$4 \mathrm{~ms} \quad$ (c)

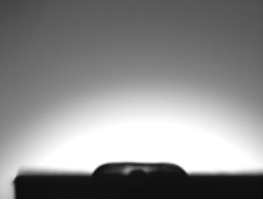

$10 \mathrm{~ms} \quad$ (f)

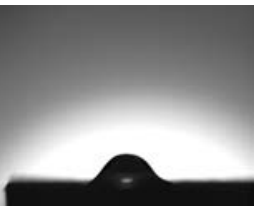

$16 \mathrm{~ms} \quad$ (i)

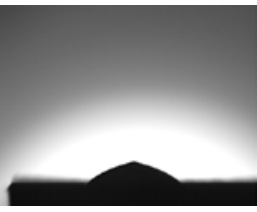

$12.902 \mathrm{~s} \quad(\mathrm{l})$
Fig. 3 Images of water droplet impact on a flat smooth surface $\left(D_{0}=2.82\right.$ $\mathrm{mm}, T_{s}=-10^{\circ} \mathrm{C}, v_{0}=0.77 \mathrm{~m} / \mathrm{s}$, and $T_{d}=5^{\circ} \mathrm{C}$ )

The impact process of a water droplet $(D=2.82 \mathrm{~mm})$ on a varied channel textured surface [20] with Aculon coating at temperature of $-10^{\circ} \mathrm{C}$ is shown in Fig. 4. It was very similar to the smooth surface case with a lamella outside of the droplet formed right after impact, and then a ring formed. This means a large proportion of the droplet stays in the outside ring instead of the inside lamella (Fig. $4 \mathrm{~d}$ ). The first spreading process lasted about $6 \mathrm{~ms}$, and the maximum spreading diameter was $4.28 \mathrm{~mm}$ (Fig. $4 \mathrm{~b}-\mathrm{d}$ ). The retraction process started at $8 \mathrm{~ms}$ (Fig. 4 e). Since the coated varied channel textured surface is hydrophobic, the height of the droplet is larger than a smooth surface during the retraction process (Fig. 4 e-h). The dynamic phase lasted about $532 \mathrm{~ms}$. Then the ice nucleation process is initiated and lasts for about $21.3 \mathrm{~s}$ (Fig. $4 \mathrm{i}-\mathrm{m}$ ). The droplet freezing process initiated at the liquid-solid interface (Fig. $4 \mathrm{i}$ ), and it propagated to the top of the droplet (Fig. $4 \mathrm{j}-\mathrm{l}$ ). A small tip was formed on the top of the droplet at the end of the ice nucleation phase (Fig. $4 \mathrm{~m}$ ). Compared with the total icing time on the smooth surface, the total icing time on this very hydrophobic surface is much longer under the same conditions.
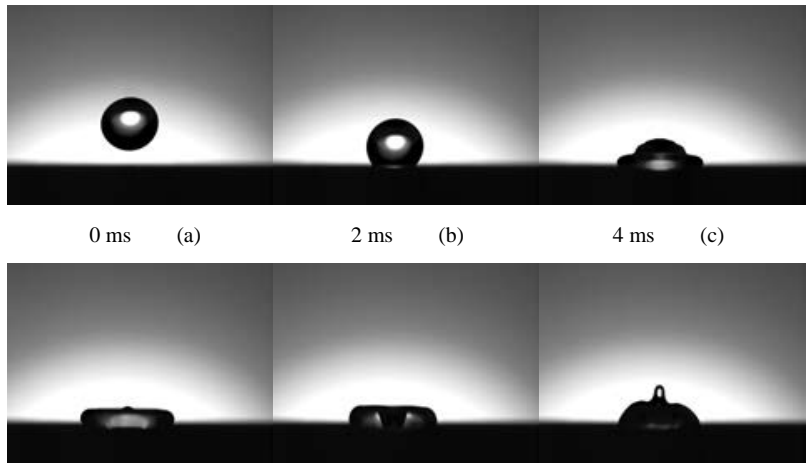

$\begin{array}{lllll}6 \mathrm{~ms} & \text { (d) } & 8 \mathrm{~ms} & \text { (e) } & 10 \mathrm{~ms} \quad \text { (f) }\end{array}$

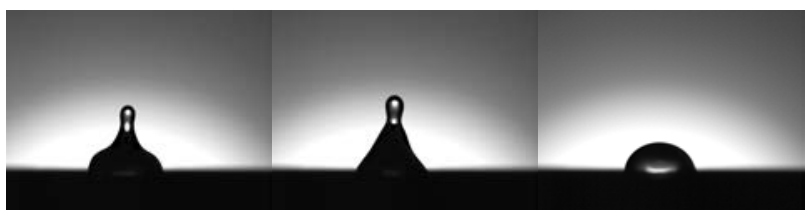

$12 \mathrm{~ms} \quad$ (g) $\quad 14 \mathrm{~ms} \quad$ (h) $532 \mathrm{~ms} \quad$ (i)

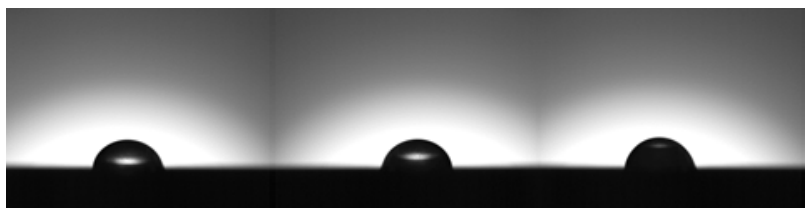

(j)

$5.694 \mathrm{~s}$

(k)

$12.824 \mathrm{~s}$

(1)

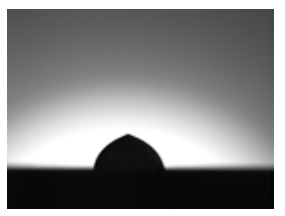

$21.324 \mathrm{~s} \quad(\mathrm{~m})$

Fig. 4: Images of water droplet impact on a flat coated varied channel surface $\left(D_{0}=2.82 \mathrm{~mm}, T_{s}=-10^{\circ} \mathrm{C}, v_{0}=0.77 \mathrm{~m} / \mathrm{s}\right.$, and $\left.T_{d}=5^{\circ} \mathrm{C}\right)$

The droplet nucleation experiment is performed with varying droplet impact speed, droplet diameter, sample surface temperature, and surface wettability. The experiments are performed to find out the relationship between different factors and droplet overall icing times. Five runs of experiments are conducted at each experimental condition. The following figures show the experimental result and analysis.

Fig. 5 indicates how the droplet icing time varies with respect to static contact angle and temperature. As the static contact angle increases, the icing time increases. The icing time decreases with decreasing temperature. Since the water droplet spreads less, oscillates longer, and partially sits on the hydrophobic surface with a low wettability, the contact area at 
solid-liquid interface is much smaller than a hydrophilic surface. The surface energy at the solid-liquid interface is lower when the contact angle is small, so the ice formation initiates earlier on a smooth surface than a hydrophobic surface. The total icing time is much longer on a hydrophobic surface due to a smaller solid-liquid contact area which means a smaller heat transfer rate.

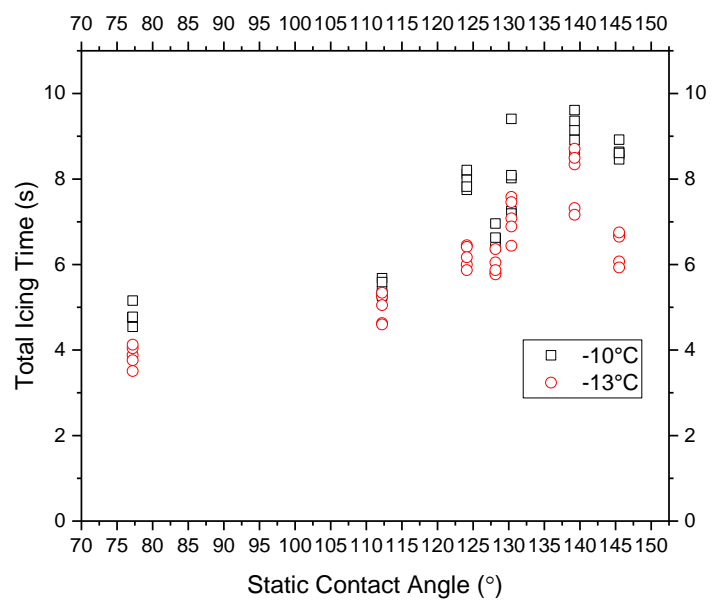

Fig. 5 Droplet icing time vs. Static contact angle at impact speed $=0.77 \mathrm{~m} / \mathrm{s}$ when the surface temperature is $-10{ }^{\circ} \mathrm{C}$ and $-13^{\circ} \mathrm{C}$.

Fig. 6 shows how the water droplet total icing time changes with respect to static contact angle at impact velocity of 0.77 $\mathrm{m} / \mathrm{s}, 0.99 \mathrm{~m} / \mathrm{s}$, and $1.17 \mathrm{~m} / \mathrm{s}$. From the figure, the total icing time decreases as the impact velocity increases. Since the impact velocity increases, the droplet spreads faster and the maximum contact area increases due to higher initial kinetic energy. Since the contact area and time during the dynamic phase increase while increasing the impact velocity, the heat transfer rate from droplet to the surface increases. The droplet may also penetrate into micro-grooves on the hydrophobic surface while increasing the impact velocity. In that case, the droplet penetration would also increase the heat transfer rate from droplet to the surface.

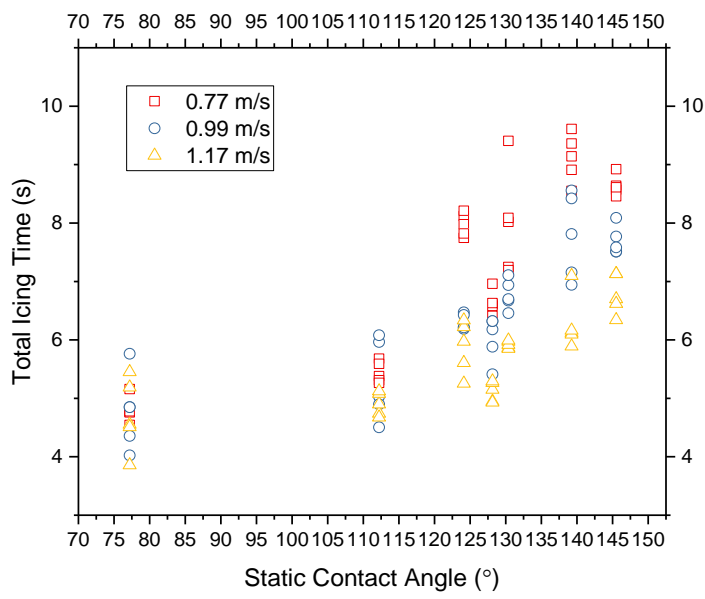

Fig. 6 Droplet icing time vs. Static contact angle at $-10{ }^{\circ} \mathrm{C}$ when the impact speed is $0.77 \mathrm{~m} / \mathrm{s}, 0.99 \mathrm{~m} / \mathrm{s}$, and $1.17 \mathrm{~m} / \mathrm{s}$.
Fig. 7 shows the relationship between the total icing time and droplet diameter which are $1.80 \mathrm{~mm}, 2.82 \mathrm{~mm}$, and 4.11 $\mathrm{mm}$. When increasing the droplet diameter and surface hydrophobicity, the droplet icing time increases. Since the volume of the droplet increases when increasing the diameter, more time and overall heat transfer are needed to fully freeze the droplet.

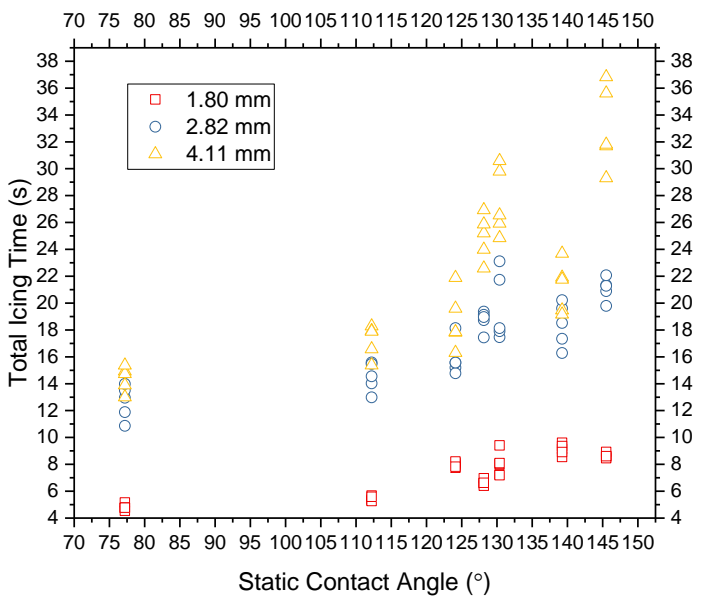

Fig. 7: Droplet icing time vs. static contact angle at $-10^{\circ} \mathrm{C}$ when the droplet diameter is $1.80 \mathrm{~mm}, 2.82 \mathrm{~mm}$, and $4.11 \mathrm{~mm}$.

\section{CONCLUSION}

This paper investigated the effects of surface wettability, droplet impact speed, surface temperature, and droplet diameter on the total icing time on surfaces. The experimental results demonstrated that when the surface wettability decreases, the total icing time increases. Since the water droplet spreads less, oscillates longer, and partially sits on surfaces with low wettability, the contact area at the solid-liquid interface is much smaller which means a lower heat transfer rate. The total icing time decreases with decreasing temperature, increasing impact velocity or decreasing droplet diameter. The water droplet spreads more and oscillates longer with increasing droplet size because the larger droplet contains more kinetic energy. Since the contact area and time during the dynamic phase increase while increasing the impact velocity, the heat transfer rate from droplet to the surface increases. So increasing droplet diameter, decreasing droplet impact speed, or increasing surface hydrophobicity can decrease or delay the droplet icing time.

\section{ACKNOWLEDGMENT}

Financial support for this research by Petroleum Research Newfoundland \& Labrador (PRNL) and the Natural Sciences and Engineering Research Council of Canada (NSERC) are gratefully appreciated.

\section{REFERENCES}

[1] Sojoudi, H., Wang, M., Boscher, N. D., Mckinley, G. H. and Gleason, K. K. "Durable and scalable icephobic surfaces: similarities and distinctions from superhydrophobic surfaces”, Soft Matter, 2016 Vol 12, pp. 1938-1963. 
[2] Bahadur, V., Mishchenko, L., Hatton, B., Taylor, A. J., Aizenberg, J., and Krupenkin, T., 2011. "Predictive Model for Ice Formation on Superhydrophobic Surfaces” Langmuir 27, pp. 14143-14150.

[3] Yamada, Y., Ikuta, T., Nishiyama, T., Takahashi, K., and Takata, Y., "Droplet Nucleation on a Well-Defined Hydrophilic -Hydrophobic Surface of $10 \mathrm{~nm}$ Order Resolution”, Langmuir 2014, Vol 30, pp. 14532-14537.

[4] Civil Aviation Authority. Aircraft Icing Handbook, 2000.

[5] Volat, C. and Farzaneh, M. "De-icing/Anti-icing Techniques for Power lines: Current Methods and Future Direction.” IWAIS XI, Montreal, June 2015.

[6] Sullivan, C.R., Petrenko, V. F., McCurdy, J. D. and Kozliouk, V. "Breaking the ice: de-icing power transmission lines with highfrequency, high-voltage excitation”. IEEE Industry Applications Magazine, Vol. 9, pp. 49-54.

[7] H. Liu, X. Gu, and W. Tang. "Icing and Anti-Icing of Railway Contact Wires”. Reliability and Safety in Railway. 2012.

[8] Meuler, A. J., Smith, J. D., Varanasi, K. K., Mabry, J. M., Mckinley, G. H., and Cohen, R. E. "Relationship between Water Wettability and Ice Adhesion”. ACS Appl. Mater. Interfaces, 2010, 2(11), pp. 3100-3110.

[9] Mishchenko, L., Hatton, B., Bahadur, V., Taylor, A., Krupenkin, T., and Aizenbery, J., 2010. "Design of Ice-free Nanostructured Surfaces Based on Repulsion of Impacting Water Droplets”, ACS Nano 4(12), pp. 76997707.
[10] Yoshimitsu, Z., Nakajima, A., Watanabe, T. and Hashimoto, K. "Effects of Surface Structure on the Hydrophobicity and Sliding Behavior of Water Droplets”. Langmuir 2002, 18, 5818-5822.

[11] Johnson, R. E., Jr.; Dettre, R. H. "In Wetting of Low Energy Surfaces”, Marcel Dekker: New York, NY, 1993; pp. 2-71.

[12] Wang, S., Liu, K., Yao, X. and Jiang, L. "Bioinspired Surfaces with Superwettability: New Insight on Theory, Design and Applications". American Chemical Society, 2015, 115, 8230-8293.

[13] Malavasi, I., Veronesi, F., Caldarelli, A., Zani, M., Raimondo, M. and Marengo, M. "Is a Knowledge of Surface Topology and Contact Angles Enough to Define the Droplet Impact Outcome?” Langmuir, 2016, 32, 6255-6262.

[14] Shi, Z., Liu, Z. Song, H. and Zhang, X. "Prediction of Contact Angle for Hydrophobic Surface Fabricated with Micro-Maching Based on Minimum Gibbs Free Energy”. Applied Surface Science, 2016, 364, 597-603.

[15] Mao, T., Kuhn, D. C. S. and Tran, H. "Spread and Rebound of Liquid Droplets Upon Impact on Flat Surfaces”. AICHE Journal, 1997, Vol. 43, No. 9.

[16] Hobbs, P. V. "Ice Physics", Oxford Classic Texts in the Physical Science.

[17] Cui, C., Collier, B., Duan, X., Poduska, K., "hydrophobic Steel Surfaces with Micron-scale and Sub-micron Structures from laser Fabrication”, 2nd Thermal and Fluid Engineering Conference, April 2-5, 2017, Las Vegas, NV, US 